\title{
FORMULATION OF POLY HERBAL NOVEL DRUG DELIVERY SYSTEM FOR ANTI RHEUMATOID ARTHRITIS
}

${ }^{1}$ L. Tamilselvi, Post graduate Student, Department of Pharmacognosy, Periyar College of Pharmaceutical Sciences, Tiruchirappalli, Tamil Nadu, India. Phone No: 8667745329, E-Mail. Id: nijatamilselvi1997@gmail.com

${ }^{2}$ Dr. R. Senthamarai, Professor \& Principal, Department of Pharmacognosy, Periyar College of Pharmaceutical Sciences, Tiruchirappalli, Tamil Nadu, India. Phone No: 0432 245991, E-mail. Id: periyarcps@gmail.com

${ }^{3}$ Dr. A.M. Ismail, Distinguished Professor, Department of Pharmacy practice, Periyar College of Pharmaceutical Sciences, Tiruchirappalli, Tamil Nadu, India. Phone no: 0432 245991, E-Mail. Id: periyarcps@gmail.com

${ }^{4}$ Dr. T. Shri Vijaya Kirubha, Professor \& Head, Department of Pharmacognosy, Periyar College of Pharmaceutical Sciences, Tiruchirappalli, Tamil Nadu, India. Phone No: 9443494665 ,

Corresponding Author: L. Tamilselvi, Post Graduate Student, Department of Pharmacognosy, Periyar College of Pharmaceutical Sciences, Tiruchirappalli, Tamil Nadu, India.

Type of Publication: Original Research Article 


\begin{abstract}
Novel herbal drug delivery system opens new vistas for delivery of herbal drugs at right place, at right concentration, for right period of time and also gives scientific angle to verify the standardization of herbal drug. Herbal Transdermal patches can develop valuable assessment and drug safety by additional site specific the way and temporal position in the body's imperative to reduce the number and size of doses required to achieve the objective of systemic medication during topical application to the intact skin surface. Rheumatoid Arthritis (RA) is a chronic, progressive autoimmune disease of unknown cause. It is characterized by persistent inflammation that primarily affects the peripheral joints. In the present study, herbal transdermal patch was developed by using ethanolic extract of leaves of Cardiospermum halicacabum and rhizomes of Drynaria quercifolia that had already been widely used for the treatment of arthritis in conventional dosage forms. Evaluation of the developed patch for the effectiveness against RA was done by in vitro methods in terms of inhibition of albumin denaturation, measurement of Interleukin-6 cytokines by Enzyme-Linked Immuno Assay (ELISA). IC-50 value was determined from albumin denaturation inhibition assay. The herbal patch significantly and dosedependently inhibited Interleukin-6 cytokines. The present study revealed that the formulated polyherbal Transdermal patch will be the better drug of choice for the treatment of Rheumatoid Arthritis as compared to the conventional dosage forms.
\end{abstract}

Keywords: Transdermal patch, Rheumatoid arthritis, ELISA

\title{
INTRODUCTION:[1,9]
}

In recent years, there has been an increasing interest by researchers in the use of naturally occurring biologically active compounds of medicinal value. Before the discovery of synthetic drugs, man completely depended on the medicinal plants for the treatment of diseases. Herbs are staging a comeback, herbal renaissance is happening all over the globe and more and more people are taking note of herbal therapies to treat various kinds of ailments in place of mainstream medicine.

For a long time, herbal medicines were not considered for development as novel formulations owing to lack of scientific justification and processing difficulties. Modern phytopharmaceutical research can solve the scientific needs (such as determination of 
pharmacokinetics, mechanism of action, site of action, accurate dose required etc.) of herbal medicines to be incorporated in novel drug delivery system, such as nanoparticles, microemulsions, transdermal patch, matrix systems, solid dispersions, liposomes, solid lipid nanoparticles and so on. The herbal drugs can be utilized in a better form with enhanced efficacy by incorporating them in modern dosage forms. This can be achieved by designing novel drug delivery systems for herbal constituents.

Transdermal drug delivery has made an important contribution to medical practice. It is a medicated patch that delivers a specific amount of medication through the skin into the blood stream. An advantage of a transdermal drug delivery route over other types of medication delivery is that the patch provides a controlled release of the medication into the patient, usually through either a porous membrane covering a reservoir of medication or through body heat melting thin layers of medication embedded in the adhesive.

Herbal Transdermal patches can develop valuable assessment and drug safety by additional site specific the way and temporal position in the body's imperative to reduce the number and size of doses required to achieve the objective of systemic medication during topical application to the intact skin surface.

Rheumatoid Arthritis (RA) is a chronic, progressive autoimmune disease of unknown cause. It is characterized by persistent inflammation that primarily affects the peripheral joints. The allopathic system of medicine includes two conventional lines of treatment for rheumatoid arthritis, which come along with certain side effects. Hence, turning to safe, effective and timetested herbal drug formulation would be a preferable option.

Apart from the conventional treatment strategies using non steroidal anti-inflammatory drugs, disease modifying antirheumatic drugs and glucocorticoids, newer and safer drugs are continuously being searched, as long term usage of these drugs have resulted in adverse effects. Alternative medicine provides another approach for treatment of RA and currently a number of medicinal plants are under scientific evaluation to develop a novel drug. 


\section{MATERIALS \& METHODS:}

\section{Collection of plant material}

The leaves of Cardiospermum halicacabum were collected from Tiruchirappalli district and the rhizomes of Drynaria quercifolia were collected from Yercaud of Tamil Nadu in the month of June 2021.

\section{Identification and authentication of plant material}

The collected specimens were botanically identified and authenticated by a Botanist. The leaf was identified as Cardiospermum halicacabum (Sapindaceae) and the rhizome was identified as Drynaria quercifolia (Polypodiaceae).

\begin{tabular}{ll}
\multicolumn{2}{l}{ Plant Profile } \\
Vernacular names \\
Englis] & - Balloon vine \\
Tamil & - Moedakottan \\
Malayalam & - Jyotishmati \\
Telugu & - Buddakaakaraeega \\
Bengali & - Lataphatkar \\
Hindi & - Kanphuti \\
Sanskrit & - Jyotishmati \\
Assam & - Kopalphuta
\end{tabular}

Taxonomical classification

Kingdom : Plantae

Phylum : Tracheophytes

Subphylum : Angiosperms

Class : Eudicots

Order : Sapindales

Family : Sapindaceae

Genus : Cardiospermum

Species : halicacabum

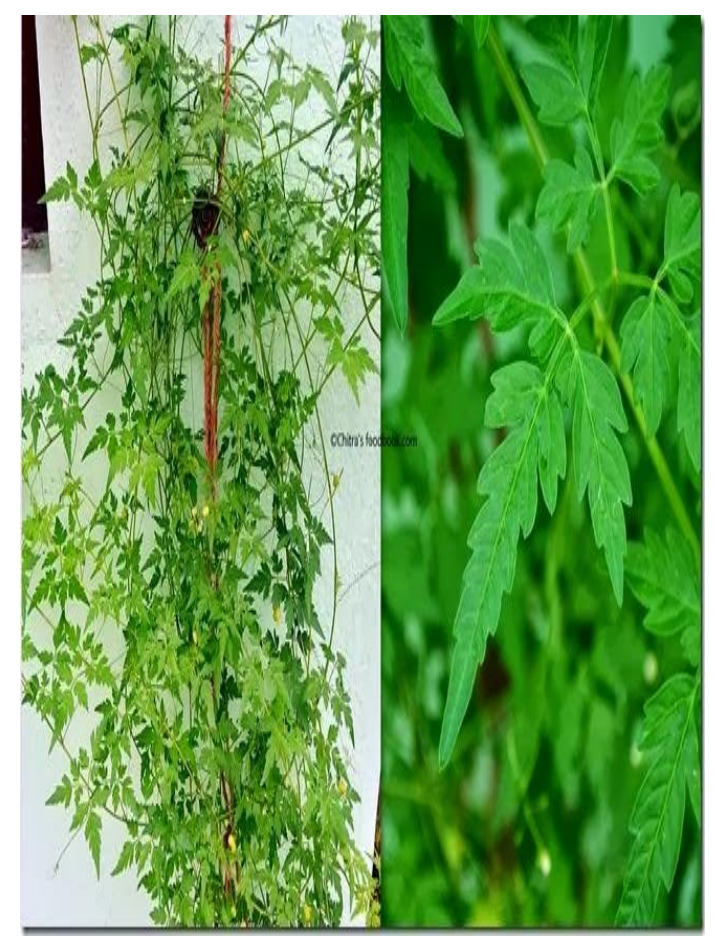

Fig.1 Leaves of Cardiospermum halicacabum 
It has been reported to possess potential medicinal values used in the treatment of rheumatism, chronic bronchitis and stiffness of the limbs and snake bite. The plant is claimed to be useful for rheumatism.

Vernacular names ${ }^{[3,4]}$

$\begin{array}{ll}\text { English } & \text { - Oak leaf fern } \\ \text { Tamil } & \text { - Mudavattukal } \\ \text { Malayalam } & \text { - Pannakilhannumanavala } \\ \text { Bengali } & \text { - Garur } \\ \text { Hindi } & \text { - Asvakatri } \\ \text { Sanskrit } & \text { - Ashvakatri }\end{array}$

TAXONOMICAL CLASSIFICATION

Kingdom : Plantae

Phylum : Tracheophyta

Class : Polypodiopsida

Order : Polypodiales

Family : Polypodiaceae

Genus : Drynaria

Species : quercifolia

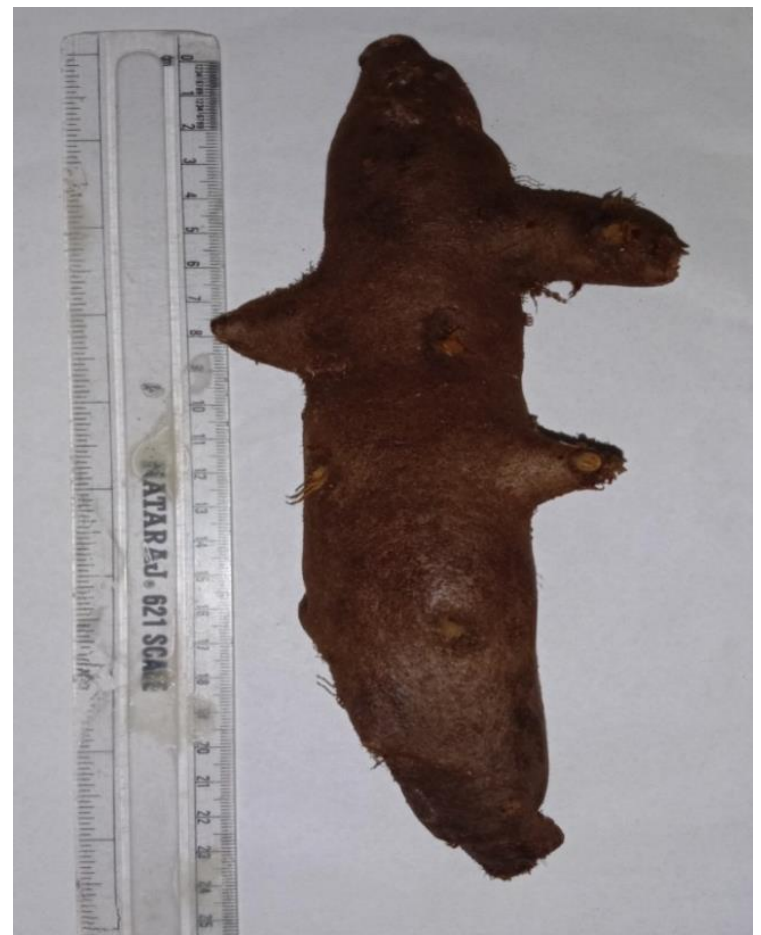

Fig.2 Rhizome of Drynaria quercifolia

Traditionally reported to be used for the treatment of various diseases like typhoid fever, chronic jaundice, headache, cough, cholera and skin diseases. Consumption of Drynaria quercifolia can help to heal and strengthen broken bones and also be used to promote the treatment of bone fracture.

\section{Formulation development ${ }^{[7]}$}

Transdermal patches were prepared by using alcoholic extract of leaves of Cardiospermum halicacabum and rhizome of Drynaria quercifolia in (60:40) ratio and polymer. Weighed quantity of polymer was dissolved in calculated quantity of water and heated on a water bath. Calculated amount of extract was added to the above mixture and stirred well until a homogenous mixture was formed. Then calculated amount of permeation enhancer and glycerin 
were added. The resultant mixture was poured into a petridish and air dried at room temperature for $24 \mathrm{hrs}$. The patches were then peeled off from the petridish with the help of a knife and kept in desiccator.

\begin{tabular}{|l|l|}
\hline Ingredients & Quantity \\
\hline ECH + EDQ & $60: 40$ \\
\hline $\begin{array}{l}\text { Hydroxy } \\
\text { Propyl Methyl } \\
\text { Cellulose E5 } \\
\text { LV (mg) }\end{array}$ & 500 \\
\hline $\begin{array}{l}\text { DiMethyl } \\
\text { Sulfoxide } \\
\text { (DMSO) (ml) }\end{array}$ & 0.3 \\
\hline Glycerin (ml) & 0.3 \\
\hline Water (ml) & q.s \\
\hline
\end{tabular}

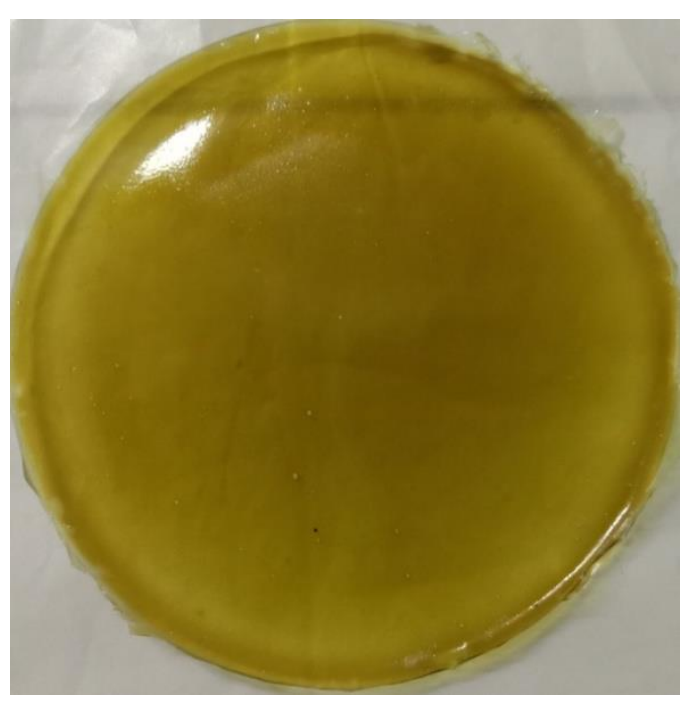

Fig.3 Herbal Transdermal patch

\section{Calculation}

Diameter of glass plate $\quad=X \mathrm{~cm}$

Radius of glass plate $\quad=\mathrm{Y} \mathrm{cm}$

Area of glass plate $\quad=\pi r^{2}(\pi=3.14)$

$\begin{aligned} & =3.14 \times(\mathrm{y}) \\ & =\mathrm{Z} \mathrm{cm} \\ \mathrm{Z} / \mathrm{X}=\text { Area/diameter } & =\text { capacity }(\mathrm{ml})\end{aligned}$

\section{Physico chemical evaluation of Transdermal Patch ${ }^{[7,8]}$}

Formulated patches were subjected to the preliminary evaluation tests. Patches with any imperfections, entrapped air, or differing in thickness, weight (or) content uniformity were excluded from further studies. 


\section{Uniformity of weight}

This was done by weighing five different patches of individual batch taking the uniform size at random and calculating the average weight of three. The tests were performed on patch which was dried at $60^{\circ} \mathrm{C}$ for $4 \mathrm{hrs}$ prior to testing.

\section{Thickness of the Patch}

The thickness of the patch was assessed by using digital vernier caliper at different points of the patch. From each formulation three randomly selected patches were used. The average value for thickness of a single patch was determined.

\section{Drug content determination}

The patches were taken and added to a beaker containing $100 \mathrm{ml}$ of $\mathrm{D}$.W. The medium was stirred magnetic bead for 5 hrs. The solution was later filtered and analyzed for drug content with proper dilution at $382 \mathrm{~nm}$ spectrophotometrically.

\section{Folding Endurance}

This was determined by repeatedly folding one patch at the same place till it broke. The number of times the patch could be folded at the same place without breaking gave the value of folding endurance.

\section{Percentage Moisture uptake}

The patch were weighed accurately and placed in desiccators containing aluminium chloride. After $24 \mathrm{hrs}$, the patch were taken out and weighed. The percentage moisture uptake was calculated as the difference between final and initial weight. With respect to initial weight. It is calculated by using following formula.

$$
\text { Final weight - Initial weight }
$$

$$
\begin{aligned}
& \text { Percentage moisture content }=\quad \longrightarrow 100 \\
& \text { Initial weight }
\end{aligned}
$$

\section{Percentage Moisture content}

The patch were weighed and kept in desiccators containing calcium chloride. After $24 \mathrm{~h}$ the patch were taken out and weighed. The percentage moisture content was calculated using the following formula. 
Initial weight -Final weight

Percentage moisture content $=$ X 100

Initial weight

\section{Determination of surface $\mathrm{pH}$}

The patches were allowed to swell by keeping them in contact with $1 \mathrm{ml}$ of distilled water for $2 \mathrm{hrs}$ at room temperature and $\mathrm{pH}$ was noted down by bringing the electrode in contact with the surface of the patch, allowing it to equilibrate for $1 \mathrm{~min}$.

\section{Percent Elongation}

When stress is applied, a patch sample stretches and this is referred to as strain. Strain is basically the deformation of patch divided by original dimension of the sample. Generally elongation of patch increases as the plasticizer content increases. It is calculated by using following formula.

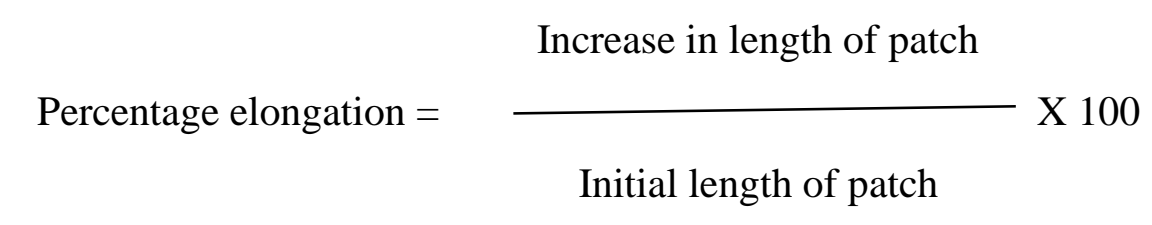

\section{Tensile strength}

Tensile strength is the maximum stress applied to a point at which the patch specimen breaks. It is calculated by the applied load at rupture divided by the cross sectional area of the strip as given in the equation below

Load at failure

$\begin{array}{ll}\text { Percentage elongation }= & \text { X } 100 \\ \text { Patch thickness } x \text { Patch width } & \end{array}$ 


\section{Anti-inflammatory activity - Inhibition of albumin denaturation ${ }^{[5,6]}$ \\ Materials Required}

Acetyl salicylic acid, Bovine Serum Albumin (BSA) were purchased from Sigma Aldrich, USA. 10x Phosphate Buffered Saline (PBS) was purchased from Himedia, India.

\section{Procedure}

$500 \mu \mathrm{L}$ of $1 \%$ bovine serum albumin was added to formulations $(500,250,100,50$ and $10 \mu \mathrm{g} / \mathrm{mL}$ ) of test sample. This mixture was kept at room temperature for $10 \mathrm{~min}$, followed by heating at $51{ }^{\circ} \mathrm{C}$ for $20 \mathrm{~min}$. The resulting solution was cooled down to room temperature and absorbance was recorded at $660 \mathrm{~nm}$. Acetyl salicylic acid was taken as a positive control. The experiment was carried out in triplicates and percent inhibition for protein denaturation was calculated using:

$$
\% \text { Inhibition }=100-((\mathrm{A} 1-\mathrm{A} 2) / \mathrm{A} 0) \times 100)
$$

Where A1 is the absorbance of the control, A2 is the absorbance of the test sample and A0 is the absorbance of the positive control.

A dose response curve was plotted to determine the IC50 values.

\section{Measurement of IL-6 cytokines by ELISA ${ }^{[10]}$}

\section{Materials required}

RPMI medium, Fetal Bovine Serum (FBS) and antibiotic solution, Human IL-6 ELISA kits were procured from Thermofisher Scientific (USA), 1X PBS was from Hi media, (India). 6 well tissue culture plate and wash beaker were from Tarson (India).

\section{Procedure}

\section{Isolation of peripheral mononuclear cells}

Human peripheral blood was collected from the healthy volunteers in $3.8 \%$ sodium citrate-treated tubes in accordance with established institutional guidelines. Briefly, mononuclear cells were isolated by layering peripheral blood onto Lymphocyte Separating Medium (LSM). 
The leukocytes enriched buffy coat contains the mononuclear cells were collected and the presence of erythrocytes was removed by lysing with $1 \%$ RBC lysis buffer.

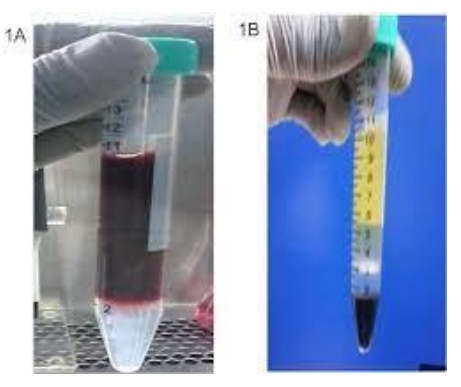

Fig.4 Isolation of PBMC

\section{ELISA}

The Peripheral Blood Mononuclear Cells (PBMC) $\left(1 \times 10^{6}\right.$ cells/ml per well in a basal medium) were seeded in to a 6 well tissue culture plate and pretreated with $208.4 \mu \mathrm{g} / \mathrm{ml}$ of F2 sample followed by stimulated with $1 \mu \mathrm{g} / \mathrm{ml}$ of LPS. The plate was incubated at $37^{\circ} \mathrm{C}$ with $5 \%$ $\mathrm{Co} 2$ incubator for $24 \mathrm{hrs}$. After incubation, the supernatants were collected and stored frozen at $-20 \circ \mathrm{C}$, until analysis. Inflammatory cytokine IL-6 levels were quantified from the same supernatant using sandwich ELISA as described in the manufacturer's protocols (Invitrogen, USA). The reaction was read at $450 \mathrm{~nm}$ in a micro plate reader (Thermofisher Scientific, USA).

\section{Results and Discussion:}

\section{Physico chemical evaluation:}

The developed herbal transdermal patches were subjected into physicochemical evaluation. The observations are given in the below table.

Table-1 Physico chemical evaluation of Herbal transdermal patch

\begin{tabular}{|c|c|c|}
\hline S. No. & Parameters & Observation \\
\hline 1. & Uniformity of weight & $0.42 \pm 0.75 \mathrm{~g}$ \\
\hline 2. & Thickness of the Patch & $0.46 \pm 0.86 \mathrm{~mm}$ \\
\hline 3. & Drug content determination & $80.25 \pm 0.74 \%$ \\
\hline 4. & Folding Endurance & $253 \pm 0.49$ \\
\hline 5. & Percentage Moisture uptake & $2.96 \pm 0.64 \%$ \\
\hline
\end{tabular}




\begin{tabular}{|c|c|c|}
\hline 6. & Percentage Moisture content & $1.247 \pm 0.06 \%$ \\
\hline 7. & Determination of surface $\mathrm{pH}$ & $7.2 \pm 0.18$ \\
\hline 8. & Percent Elongation & $88 \pm 0.72 \% \mathrm{~mm}$ \\
\hline 9. & Tensile strength & $6.134 \pm 0.72 \mathrm{~kg} / \mathrm{mm}^{2}$ \\
\hline
\end{tabular}

\section{Anti-inflammatory activity - Inhibition of albumin denaturation}

The evaluated transdermal patch was exposed to effectiveness against RA was done by in vitro methods in terms of inhibition of albumin denaturation. The results are shown in below table

Table - 2 Inhibition percentage of albumin denaturation

\begin{tabular}{|r|l|l|l|l|l|}
\hline \multicolumn{1}{|l|}{ S. No. } & \multicolumn{2}{|l|}{$\begin{array}{l}\text { Tested sample } \\
\text { concentration } \\
(\boldsymbol{\mu g} / \mathrm{ml})\end{array}$} & \multicolumn{2}{|l|}{$\begin{array}{l}\text { Inhibition percentage albumin } \\
\text { denaturation }(\%) \\
\text { (in triplicates })\end{array}$} & $\begin{array}{l}\text { Mean Value } \\
(\%)\end{array}$ \\
\hline 1. & Control & 100 & 100 & 100 & 100 \\
\hline 2. & $500 \mu \mathrm{g} / \mathrm{ml}$ & 69.41 & 70.63 & 89.08 & 76.37 \\
\hline 3. & $250 \mu \mathrm{g} / \mathrm{ml}$ & 14.33 & 16.11 & 13.02 & 14.48 \\
\hline 4. & $100 \mu \mathrm{g} / \mathrm{ml}$ & 12.69 & 12.22 & 12.27 & 12.39 \\
\hline 5. & $50 \mu \mathrm{g} / \mathrm{ml}$ & 11.56 & 8.85 & 9.41 & 9.94 \\
\hline 6. & $10 \mu \mathrm{g} / \mathrm{ml}$ & 7.40 & 8.52 & 7.91 & 7.94 \\
\hline
\end{tabular}




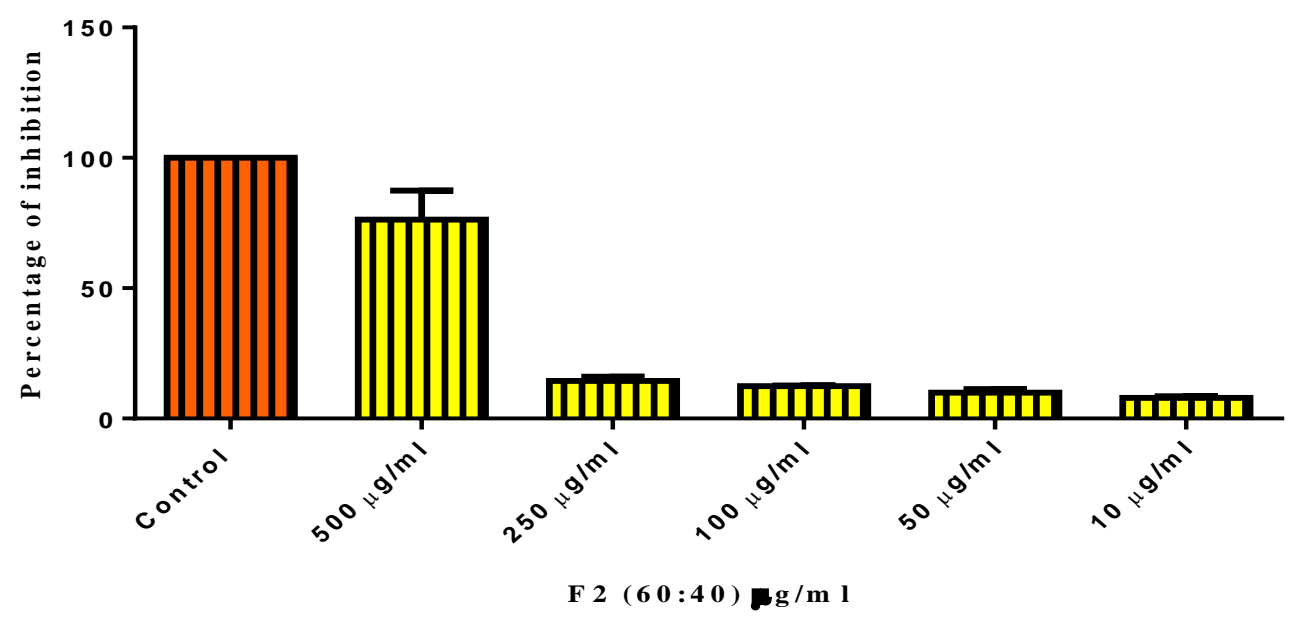

Fig. 5 Concentration dependent Inhibition of albumin denaturation

\section{Measurement of IL-6 cytokines by ELISA}

Increase in optical density of the test sample was obtained which indicates significance anti arthritic property in the developed formulation. The results are shown below

Table- 3 Optical density of the developed Polyherbal Formulation

\begin{tabular}{|l|l|r|r|r|r|r|r|}
\hline $\begin{array}{l}\text { S. } \\
\text { No. }\end{array}$ & \multicolumn{3}{|c|}{ Sample } & \multicolumn{2}{|c|}{ ODcentration of IL-6 pg/ml } & \multicolumn{3}{c|}{} \\
\hline 1. & Control & 49.19874 & 50.41071 & 43.13886 & 0.123 & 0.128 & 0.098 \\
\hline 2. & LPS & 177.6681 & 166.5179 & 166.5179 & 0.653 & 0.681 & 0.607 \\
\hline 3. & F2 + LPS & & & & & & \\
& & 70.2871 & 61.80328 & 63.50004 & 0.210 & 0.175 & 0.182 \\
\hline
\end{tabular}



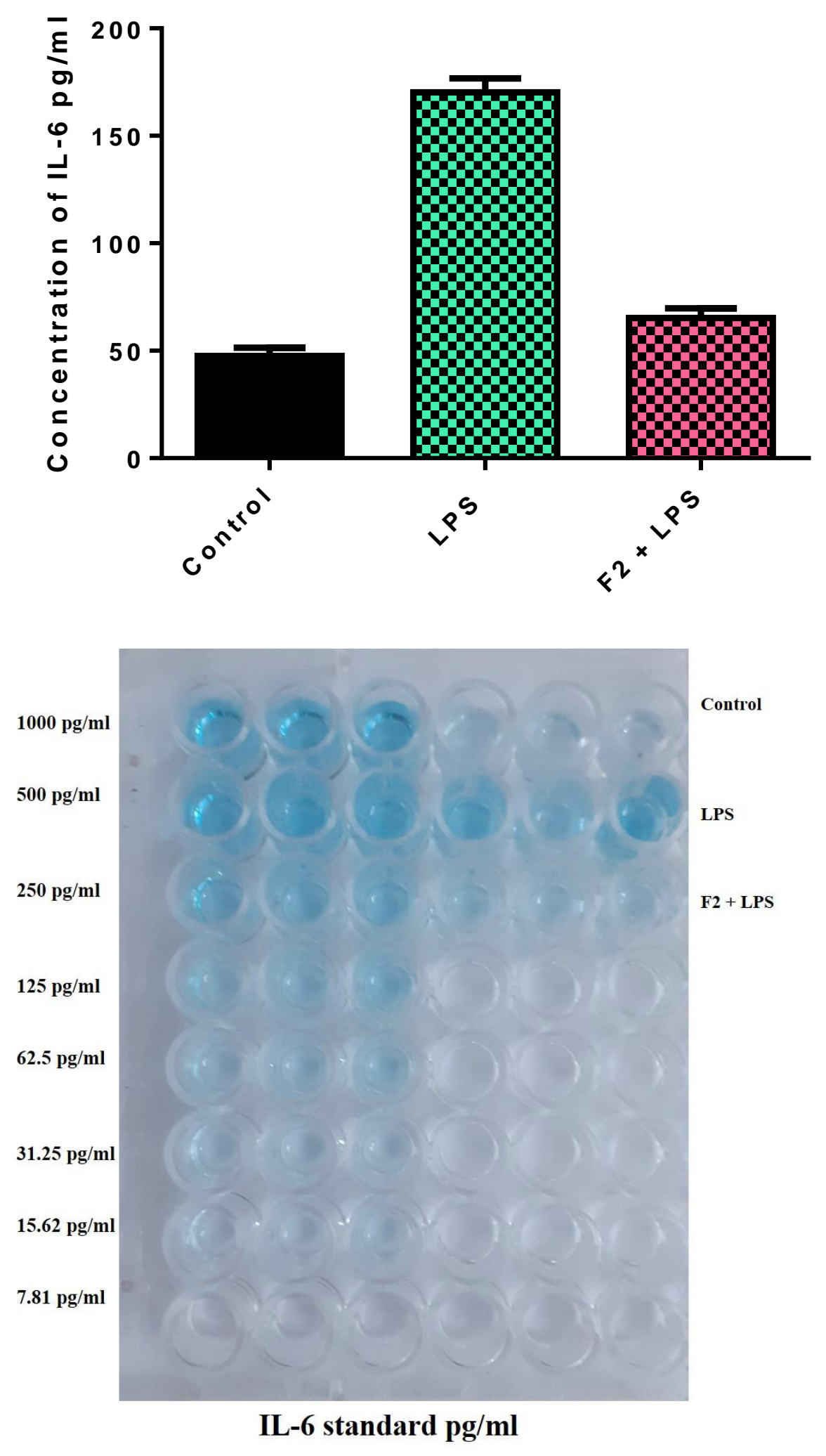

Fig.6 PBMC with drug samples in 96 Well plates 


\section{Conclusion:}

The present pilot study has revealed that the Formulated Polyherbal Transdermal patch will be the better drug of choice for the treatment of Rheumatoid Arthritis as compared to the conventional dosage forms. The potency of the developed formulation shall be subjected to in vivo screening methods in future.

\section{References:}

1. G Prasanna, R Anuradha, "A Comprehensive Review on Phytopharmacological Activities of Drynaria quercifolia L. " International Journal of Pharmacognosy and Phytochemical Research 2016; 8(8); pp. 1304-1313.

2. The Wealth of India. A dictionary of Indian raw materials and industrial products, Vol. III: Ca-Ci (revised), Council of Scientific \& Industrial Research, New Delhi 1992; pp. 269-270.

3. The Wealth of India. A dictionary of Indian raw materials and industrial products, Vol. III: D-E, Council of Scientific \& Industrial Research New Delhi 1952; pp.114.

4. K.M Nadkarni , The Indian Materia Medica, Saurabh Printers Pvt. Ltd, Noida, 2013; $3^{\text {rd }}$ edition; $1 ;$ pp.271-272,466.

5. Mizushima Y, Kobayashi M. Interaction of anti-inflammatory drugs with serum proteins, especially with some biologically active proteins. Journal of Pharmacy and Pharmacology 1968;20(3):169-73.

6. Sakat S, Juvekar AR, Gambhire MN. In vitro antioxidant and anti-inflammatory activity of methanol extract of Oxalis corniculata Linn. International Journal Pharmaceutical and Pharmaceutical Sciences 2010;2(1):146-56.

7. Ansel.H.C, Loyd.A.V, Popovich.N.G, Pharmaceutical dosage forms and drug delivery systems, Transdermal drug delivery system introduction. Lippincott Williams and Willkins publication. Seventh edition, Section 8 : 646-668.

8. Syeda Ayesha Fathima, Shireen Begum, Syeda Saniya Fatima.Transdermal Drug Delivery System , International Journal of Pharmaceutical and Clinical Research 2017,vol 9(1): 35-43. 
9. Khan Daniyal, Chouhan Shivani, Khan Shoeb, Mansuri Saif, Goswami Raksha, Shrivastava Darshana, "A review on herbal transdermal patch for arthritis". International Journal of Pharmacognosy and Clinical Research. 2019; Volume 1, Issue 1: pp. 25-33.

10. Engvall E and Perlmann P. Enzyme Linked Immunosorbent assay (ELISA) quantitative assay of immunoglobulin G, Immunochemistry (1971), Volume 8, pp. $871-875$. 